\title{
Longitudinal transitions of exclusive and polytobacco electronic nicotine delivery systems (ENDS) use among youth, young adults and adults in the USA: findings from the PATH Study Waves 1-3 (2013- 2016)
}

\author{
Cassandra A Stanton (이, ${ }^{1,2}$ Eva Sharma (1) , ${ }^{1}$ Kathryn C Edwards (ㄷ), \\ Michael J Halenar (1) , ${ }^{1}$ Kristie A Taylor 이, ${ }^{1}$ Karin A Kasza (ㅇ), ${ }^{3}$ Hannah Day, ${ }^{4}$ \\ Gabriella Anic, ${ }^{4}$ Lisa D Gardner (1) , ${ }^{4}$ Hoda T Hammad, ${ }^{4}$ Maansi Bansal-Travers (1), ${ }^{3}$ \\ Jean Limpert, ${ }^{4}$ Nicolette Borek, ${ }^{4}$ Heather L Kimmel $\quad 10,{ }^{5}$ Wilson M Compton, ${ }^{5}$ \\ Andrew Hyland ${ }^{3}$
}

\begin{abstract}
- Additional material is published online only. To view please visit the journal online (http://dx.doi.org/10.1136/ tobaccocontrol-2019-055574)
\end{abstract}

${ }^{1}$ Behavioral Health and Health Policy Practice, Westat, Rockville MD, USA

${ }^{2}$ Department of Oncology, Georgetown University Medical Center, Washington, DC, United States

${ }^{3}$ Department of Health Behavior Roswell Park Comprehensive Cancer Center, Buffalo, NY, United States

${ }^{4}$ Office of Science, Center for Tobacco Products, Food and Drug Administration, Silver Spring, MD, United States ${ }^{5}$ National Institute on Drug Abuse, National Institutes of Health, Bethesda, MD, United States

Correspondence to

Dr Cassandra A Stanton, Behavioral Health and Health Policy, Westat, Rockville, MD 20850, USA;

cassandrastanton@westat.com

Received 16 December 2019 Revised 8 January 2020 Accepted 15 January 2020
Check for updates

(C) Author(s) (or their employer(s)) 2020. No commercial re-use. See rights and permissions. Published by BMJ.

To cite: Stanton CA

Sharma E, Edwards KC, et al. Tob Control

2020:29:s147-s154.

\section{ABSTRACT}

Objective Electronic nicotine delivery systems (ENDS; including e-cigarettes) are rapidly evolving in the US marketplace. This study reports cross-sectional prevalence and longitudinal pathways of ENDS use across 3 years, among US youth (12-17 years), young adults (18-24 years) and adults $25+$ ( 25 years and older).

Design Data were from the first three waves (20132016) of the Population Assessment of Tobacco and Health Study, a nationally representative, longitudinal cohort study of US youth and adults. Respondents with data at all three waves (youth, $n=11046$; young adults, $n=6478$; adults $25+, n=17$ 188) were included in longitudinal analyses

Results Weighted cross-sectional ever use of ENDS increased at each wave. Across all three waves, young adults had the highest percentages of past 12-month, past 30-day (P30D) and daily P30D ENDS use compared with youth and adults $25+$. Only about a quarter of users had persistent P30D ENDS use at each wave. Most ENDS users were polytobacco users. Exclusive Wave 1 ENDS users had a higher proportion of subsequent discontinued any tobacco use compared with polytobacco ENDS users who also used cigarettes.

Conclusions ENDS use is most common among young adults compared with youth and adults 25+. However, continued use of ENDS over 2 years is not common for any age group. Health education efforts to reduce the appeal and availability of ENDS products might focus on reducing ENDS experimentation, and on reaching the smaller subgroups of daily ENDS users to better understand their reasons for use.

\section{INTRODUCTION}

Electronic nicotine delivery systems (ENDS), including e-cigarettes, are battery-operated products that produce an aerosolised mixture containing nicotine, flavourings, propylene glycol, glycerin and/or other additives that the user inhales. ${ }^{1}$ In the USA, the tobacco marketplace has seen a rapidly evolving array of ENDS products. ${ }^{2}$ US representative cross-sectional surveys have shown ever use of e-cigarettes is significantly increasing among youth (12-17 years). ${ }^{3-8}$ For both high school students and middle school students, ENDS have been the most frequently used tobacco products since 2014. ${ }^{367910}$ The 2011-2018 National Youth Tobacco Survey data show significant non-linear increases in past 30-day (P30D) ENDS use among high school students from $1.5 \%$ to $20.8 \%$ and among middle school students from $0.6 \%$ to $4.9 \% .^{7}$ Aggregated initiation rates of past 12-month (P12M) ENDS use across the approximate 3 years' time span (20132016) of Wave 1 to Wave 3 (W1-W3) of the Population Assessment of Tobacco and Health (PATH) Study indicate that most ENDS initiation occurs among youth (ages 12-17) and young adults (ages 18-24) (youth, 22.7\%; young adults, 28.4\%; adults $25+, 6.7 \%)$ and that compared with other tobacco products, ENDS have shown the highest initiation rates during this time period. ${ }^{11}$ P30D ENDS use has been reported to be less frequent compared with combustible cigarette use, with the vast majority of ENDS use being non-daily. ${ }^{12-14}$

Most US youth and adult ENDS users are dual or polytobacco product users. ${ }^{1} 1516$ Among US youth, ${ }^{15} 17$ P30D use of cigarettes and ENDS is the most common product combination $(15.0 \%) .{ }^{16}$ Use of ENDS with combustible cigarettes can result in continued exposure to the toxic combustion products of traditional cigarettes and exposure to unique constituents in ENDS (eg, flavours, humectants). ${ }^{18} 19$ Tobacco users who use both ENDS and combustible cigarettes may be using ENDS to gradually substitute ENDS for cigarettes with the intention to reduce or quit cigarettes, or may be adding ENDS to existing cigarette use as a way to cope with smoke-free policies that create discomfort due to nicotine dependence. ${ }^{18}$ Data on the long-term health effects of dual combustible cigarette and ENDS use are limited, with some studies showing no reduced risk from dual use compared with cigarette smoking alone, ${ }^{20-22}$ and others suggesting dual use may be associated with more risk of negative health effects. ${ }^{23-25}$

The first aim of this study is to examine differences between each of the first three waves of 
cross-sectional weighted estimates of ENDS use from the PATH Study (2013-2016). Differences over time are reported for different definitions of ENDS use, such as ever, P12M, P30D and daily P30D ENDS use for US youth, young adults and adults $25+$. Drawing from the first three waves of longitudinal within-person data from the PATH Study, the second aim is to examine age group differences in W1-W2-W3 pathways of persistent use, discontinued use and reuptake of ENDS among W1 P30D ENDS users. The final aim of these analyses is to compare longitudinal transition pathways among W1 exclusive ENDS users, W1 ENDS polytobacco users including cigarettes (ENDS polytobacco use w/CIGS) and W1 ENDS polytobacco users who do not use cigarettes (ENDS polytobacco use w/o CIGS) to understand product transitions. Comparing longitudinal transitions among exclusive versus polytobacco ENDS users will advance our understanding of patterns of polytobacco use in the USA and critical product transitions, such as switching and complete tobacco cessation. These analyses will lay the groundwork for more robust evaluations of the potential health risks and benefits of ENDS use at the population level.

\section{METHODS}

\section{Study design and population}

The PATH Study is an ongoing, nationally representative, longitudinal cohort study of youth (ages 12-17) and adults (ages 18 or older) in the USA. Self-reported data were collected using Audio Computer-Assisted Self-Interview administered in English and Spanish. Further details regarding the PATH Study design and W1 methods are published elsewhere. ${ }^{26}{ }^{27}$ At W1, the weighted response rate for the household screener was $54.0 \%$. Among screened households, the overall weighted response rate was $78.4 \%$ for youth and $74.0 \%$ for adults at $\mathrm{W} 1,87.3 \%$ for youth and $83.2 \%$ for adults at W2 and $83.3 \%$ for youth and $78.4 \%$ for adults at W3. Details on interview procedures, questionnaires, sampling, and weighting and information on accessing the data are available at https://doi.org/10.3886/Series606. The study was conducted by Westat and approved by the Westat Institutional Review Board. All participants ages 18 and older provided informed consent, with youth participants ages 1217 providing assent while their parent/ legal guardian provided consent.

The current study reports cross-sectional estimates from 13651 youth and 32320 adults who participated in W1 (data collected 12 September 2013 through 14 December 2014), 12172 youth and 28362 adults at W2 (23 October 2014 through 30 October 2015) and 11814 youth and 28148 adults at W3 (19 October 2015 to 23 October 2016). The differences in the number of completed interviews between W1, W2 and W 3 reflect attrition due to nonresponse, mortality and other factors, as well as youth who enrol in the study at W2 or W3. ${ }^{26}$ We also report longitudinal estimates from W1 youth $(n=11046), W 1$ young adults $(n=6478)$ and W1 adults $25+(\mathrm{n}=17188)$ with data collected at all three waves. See online supplementary figure 1 for a detailed description of the analytic sample for longitudinal analysis.

\section{Measures}

\section{Tobacco use}

At each wave, adults and youth were asked about their tobacco use behaviours for cigarettes, ENDS, traditional cigars, cigarillos, filtered cigars, pipe tobacco, hookah, snus pouches, other smokeless tobacco (loose snus, moist snuff, dip, spit or chewing tobacco) and dissolvable tobacco. Participants were asked about 'e-cigarettes' at W1 and 'e-products' (e-cigarettes, e-cigars, e-pipes and e-hookah) at W2 and W3; all electronic products are referred to as ENDS in this paper. In addition, youth were asked about their use of bidis and kreteks but these data were not included in the analyses due to small sample sizes.

At W1, ENDS were described as 'e-cigarettes that look like regular cigarettes, but are battery-powered and produce vapor instead of smoke. Some common brands include NJOY, Blu, and Smoking Everywhere'. At W2 and W3, ENDS were described as 'electronic nicotine products such as e-cigarettes, e-cigars, e-pipes, e-hookahs, and personal vaporizers, as well as vape pens and hookah pens that are battery-powered, use nicotine fluid rather than tobacco leaves, and produce vapor instead of smoke. Some common brands include Fin, NJOY, Blu, e-Go and Vuse'. Participants were shown generic pictures of the product at all three waves.

\section{Outcome measures}

Cross-sectional definitions of use included ever, P12M, P30D and daily P30D use. Longitudinal outcomes included persistent ENDS use, discontinued ENDS use and reuptake of ENDS use, as well as transitions among exclusive and polytobacco ENDS users. The definition of each outcome is included in the footnote of the table/figure in which it is presented.

\section{Analytic approach}

To address Aim 1, weighted cross-sectional prevalence of ENDS use was compared across waves for each age group for ever, P12M, P30D and daily P30D use. For Aim 2, irrespective of other tobacco product use, longitudinal W1-W2-W3 transitions in P30D ENDS use were compared by age group within three separate user groups persistent any P30D ENDS use (defined as continued P30D ENDS use at W2 and W3), discontinued any P30D ENDS use (stopped ENDS use at W2 and W3 or just W3) and reuptake of any P30D ENDS use (used ENDS at W1, discontinued ENDS use at W2 and used ENDS again at W3). Finally, to address Aim 3, longitudinal W1-W2-W3 ENDS use pathways that flow through seven mutually exclusive and exhaustive transition categories were examined for W1 P30D exclusive ENDS use, W1 P30D ENDS polytobacco use w/CIGS and W1 P30D ENDS polytobacco use w/o CIGS (see online supplementary figure 2). For each aim, weighted t-tests were conducted on differences in proportions to assess statistical significance. To correct for multiple comparisons, Bonferroni post hoc tests were conducted. Given that cigarettes are the most commonly used tobacco product with the most robust evidence base of potentially harmful health consequences, ${ }^{5}$ two polytobacco use groups were examined separately to compare longitudinal transitions among polytobacco users who use and do not use cigarettes. These pathways represent building blocks that may be aggregated to reflect higher level behavioural transitions.

Cross-sectional estimates (Aim 1) were calculated using PATH Study cross-sectional weights for W1 and single-wave (pseudocross-sectional) weights for W2 and W3. The weighting procedures adjusted for complex study design characteristics and non-response. Combined with the use of a probability sample, the weighted data allow these estimates to be representative of the non-institutionalised, civilian, resident U.S population aged 12 or older at the time of each wave. Longitudinal estimates (Aims 2 and 3) were calculated using the PATH Study W3 allwaves weights. These weighted estimates are representative of the resident US population aged 12 and older at the time of W3 (other than those who were incarcerated) who were in the civilian, non-institutionalised population at W1.

All analyses were conducted using SAS Survey Procedures V.9.4 (SAS Institute). Variances were estimated using the balanced repeated replication method ${ }^{28}$ with Fay's adjustment set to 0.3 


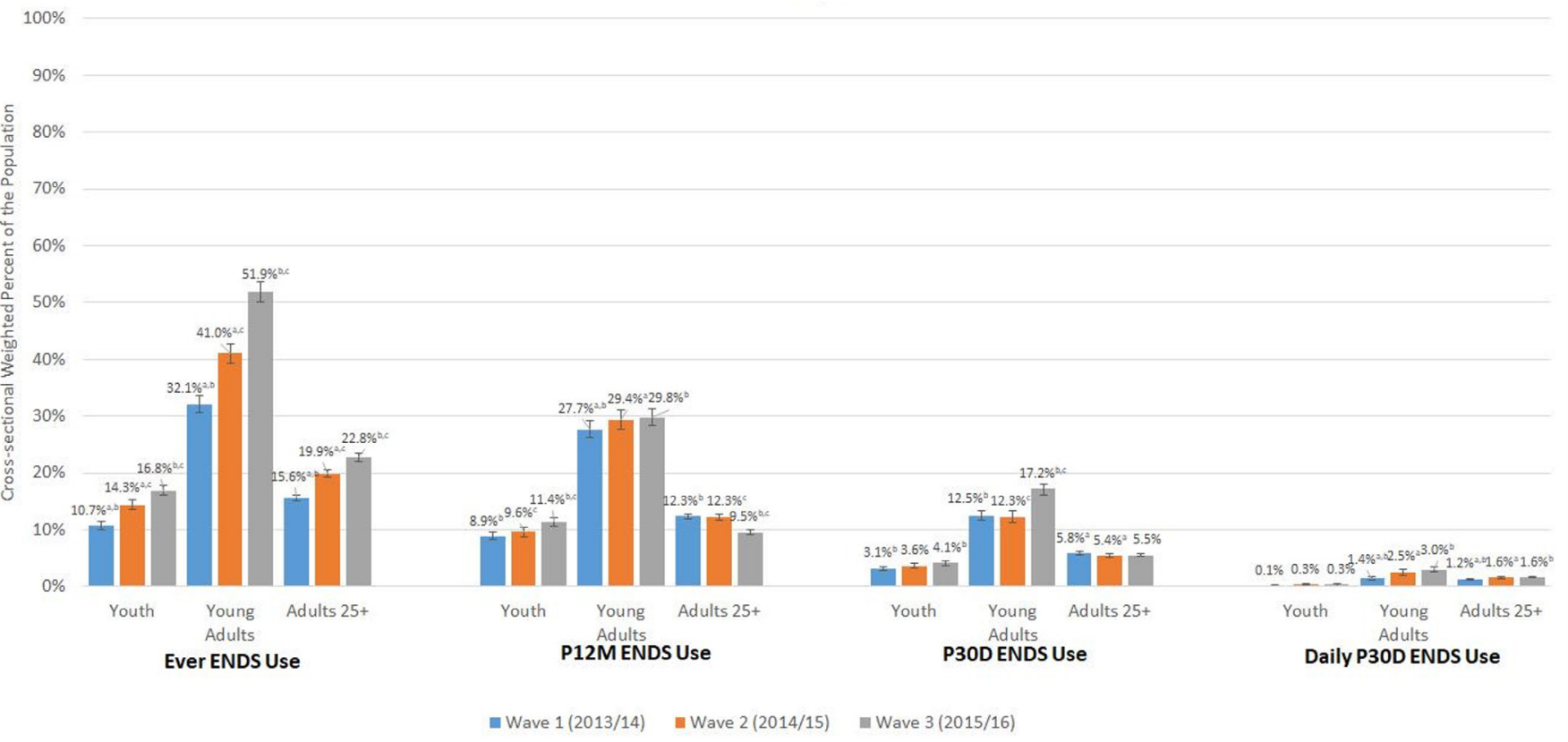

Figure 1 Cross-sectional weighted percent of ever, P12M, P30D and daily P30D electronic nicotine delivery systems (ENDS) use among youth, young adults and adults 25+ in W1, W2 and W3 of the Population Assessment of Tobacco and Health (PATH) Study.

Notes: Abbreviations: $\mathrm{P} 12 \mathrm{M}=$ past 12 -month; $\mathrm{P} 30 \mathrm{D}=$ past 30 -day; ENDS* = electronic nicotine delivery system; $\mathrm{W} 1=\mathrm{Wave} 1 ; \mathrm{W} 2=\mathrm{Wave} 2 ; \mathrm{W} 3=$ Wave 3

W1/W2/W3 ever ENDS use unweighted Ns: youth (ages 12-17) = 1,451/1,715/1,930; young adults (ages 18-24) = 3,887/3,968/4,702; adults 25+ (ages 25 and older) $=7,634 / 8,065 / 8,634$

W1/W2/W3 P12M ENDS use unweighted Ns: youth = 1,193/1,130/1,296; young adults = 3,356/2,777/2,802; adults 25+=6,062/4,957/3,741

W1/W2/W3 P30D ENDS use unweighted Ns: youth = 418/415/454; young adults =1,516/1,180/1,630; adults 25+ =2,914/2,199/2,163

W1/W2/W3 daily P30D ENDS use unweighted Ns: youth = 20/37/29; young adults =170/240/280; adults 25+ =619/639/642

X-axis shows four categories of ENDS use (ever, P12M, P30D, and daily P30D). Y-axis shows weighted percentages of W1, W2, and W3 users. Sample analyzed includes all W1, W2, and W3 respondents at each wave. All respondents with data at one wave are included in the sample for that wave's estimate and do not need to have complete data at all three waves. The PATH Study cross-sectional (W1) or single-wave weights (W2 and W3) were used to calculate estimates at each wave. Ever ENDS use is defined as having ever used ENDS, even once or twice in lifetime. P12M ENDS use is defined as any ENDS use within the past 12 months. P30D ENDS use is defined as any ENDS use within the past 30 days. Daily P30D ENDS use is defined as use of ENDS on all 30 of the past 30 days. All use definitions refer to any use that includes exclusive or polytobacco use of ENDS. adenotes significant difference at $p<0.0167$ (Bonferroni corrected for three comparisons) between W1 and W2 bdenotes significant difference at $p<0.0167$ (Bonferroni corrected for three comparisons) between W1 and W3 'denotes significant difference at $p<0.0167$ (Bonferroni corrected for three comparisons) between W2 and W3

*Respondents were asked about "e-cigarettes" at W1 and "e-products" (i.e., e-cigarettes, e-cigars, e-pipes, and e-hookah) at W2 and W3.

The logit-transformation method was used to calculate the $95 \%$ confidence intervals.

Analyses were run on the W1, W2, and W3 Public Use Files (https://doi.org/10.3886/ICPSR36498.v8).

to increase estimate stability. ${ }^{29}$ Analyses were run on the W1W3 Public Use Files (https://doi.org/10.3886/ICPSR36498.v8). Estimates with low precision (fewer than 50 observations in the denominator or with a relative standard error greater than 0.30 ) were flagged and are not discussed in the Results section.

\section{RESULTS}

\section{Cross-sectional weighted prevalence}

As shown in figure 1, across age groups, ever use of ENDS significantly increased at each wave. Prevalence of P12M ENDS use did not change in young adults across waves, although among youth it increased $2.5 \%$ from W1 to W3, and among adults $25+$ it dropped $2.8 \%$ at W3 from W1 and W2. Prevalence of P30D use did not change in youth or adults $25+$ between W2 and W3, but among young adults P30D use increased by $4.9 \%$ at W3 compared with W2. Daily P30D ENDS use among young adults increased from $1.4 \%(95 \%$ CI 1.2 to 1.7$)$ at W1 to $2.5 \%(95 \%$ CI 2.1 to 3.1$)$ at W2 and to $3 \%(95 \%$ CI 2.6 to 3.4$)$ at W3. Across all three waves, young adults had the highest percentages of ever, P12M, P30D and daily P30D ENDS use. Described differences are absolute per cent differences, not relative per cent differences.

\section{Longitudinal weighted W1-W2-W3 pathways}

Among any P30D ENDS users at W1

Among those with data at all three waves, 3.0\% (95\% CI 2.6 to 3.4 ) of youth, $12.5 \%$ (95\% CI 11.6 to 13.5$)$ of young adults and $5.8 \%$ (95\% CI 5.5 to 6.1$)$ of adults $25+$ had P30D ENDS use at W1. As illustrated in figure 2, persistent P30D ENDS use, defined as P30D ENDS use at all three waves, irrespective of concurrent use of other products, was similar across each age group. Discontinued ENDS use, defined as stopping ENDS use at W2 or W3 among W1 P30D ENDS users, was higher among young adults (62.1\% (95\% CI 58.7 to 65.5$)$ ) and adults $25+$ (63.0\% (95\% CI 60.4 to 65.4)) compared with youth $(54.1 \%$ (95\% CI 48.4 to 59.7)). ENDS reuptake, defined as ENDS use at W1, no ENDS use at W2 and ENDS use again at W3, was lowest among adults $25+(10.1 \%(95 \%$ CI 8.8 to 11.6$))$ compared with 


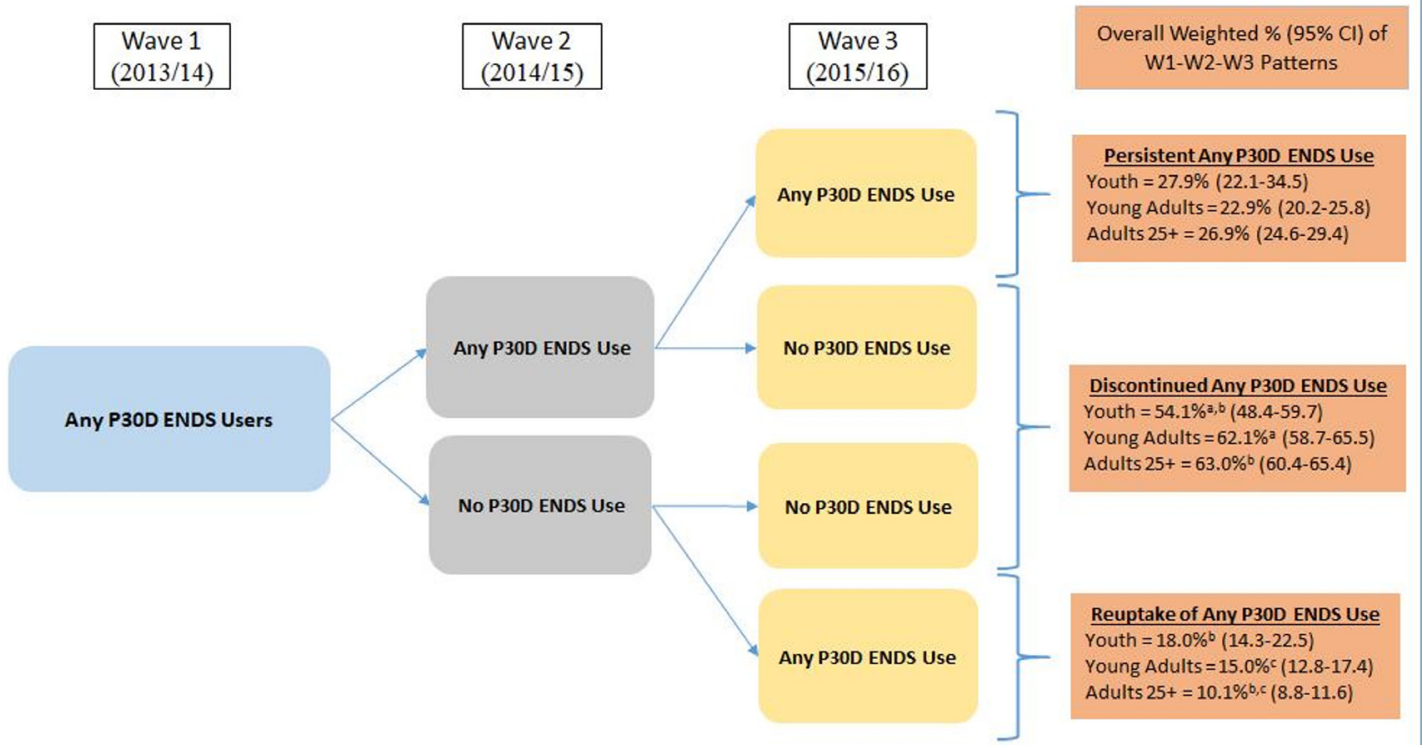

Figure 2 Patterns of W1-W2-W3 persistent any P30D ENDS use, discontinued any P30D ENDS use and reuptake of any P30D ENDS use among W1 any P30D ENDS users.

Abbreviations: $\mathrm{W} 1=$ Wave 1; W2 = Wave 2; W3 = Wave 3; P30D = past 30-day; ENDS $*$ electronic nicotine delivery system; $\mathrm{Cl}=$ confidence interval Wave 1 any P30D ENDS use weighted percentages (95\% CI) out of total U.S. population: youth (ages 12-17) $=3.0 \%$ (2.6-3.4); young adults (ages 18$25)=12.5 \%(11.6-13.5)$; adults $25+$ (ages 25 and older) $=5.8 \%(5.5-6.1)$

Analysis included W1 youth, young adults, and adults 25+ P30D ENDS users with data at all three waves. Respondent age was calculated based on age at W1. W3 longitudinal (all-waves) weights were used to calculate estimates. These rates vary slightly from those reported in Figure 1 or Supplemental Table 1 because this analytic sample in Figure 2 includes only those with data at each of the three waves to examine weighted longitudinal use and non-use pathways.

Any P30D ENDS use was defined as any ENDS use within the past 30 days. Respondent could be missing data on other P30D tobacco product use and still be categorized into the following three groups:

1) Persistent any P30D ENDS use: Defined as exclusive or ENDS polytobacco use at W2 and W3.

2) Discontinued any P30D ENDS use: Defined as any non-ENDS tobacco use or no tobacco use at either W2 and W3 or just W3.

3) Reuptake of any P30D ENDS use: Defined as discontinued ENDS use at W2 and any ENDS use at W3.

adenotes significant difference at $p<0.0167$ (Bonferroni corrected for three comparisons) between youth and young adults

${ }^{b}$ denotes significant difference at $p<0.0167$ (Bonferroni corrected for three comparisons) between youth and adults 25+

'denotes significant difference at $p<0.0167$ (Bonferroni corrected for three comparisons) between young adults and adults $25+$

*Respondents were asked about "e-cigarettes" at W1 and "e-products" (i.e., e-cigarettes, e-cigars, e-pipes, and e-hookah) at W2 and W3.

The logit-transformation method was used to calculate the $95 \% \mathrm{Cls}$.

Analyses were run on the W1, W2, and W3 Public Use Files(https://doi.org/10.3886/ICPSR36498.v8).

youth $(18.0 \%$ (95\% CI 14.3 to 22.5$))$ and young adults $(15.0 \%$ (95\% CI 12.8 to 17.4$)$ ).

Among Wave 1 P30D ENDS user types (exclusive, polytobacco users w/CIGS and polytobacco users w/o CIGS)

Among the longitudinal sample of W1 P30D ENDS users, most were ENDS users who also used another tobacco product: $63.8 \%$ (95\% CI 58.8 to 68.5 ) of youth, $87.4 \%$ (95\% CI 85.0 to 89.35 ) of young adults and $86.2 \%$ (95\% CI 84.5 to 87.7 ) of adults $25+$. Among ENDS polytobacco users, 70.6\% (95\% CI 63.1 to 77.1 ) of youth, $84.7 \%$ (95\% CI 82.1 to 86.9$)$ of young adults and $94.8 \%$ (95\% CI 93.4 to 95.9$)$ of adults $25+$ also used cigarettes. Less than half of youth and young adult ENDS users who also used cigarettes used only cigarettes and e-cigarettes, but most adults $25+(69.4 \%$ (95\% CI 66.6 to 72.0$)$ ) with ENDS polytobacco use w/CIGS used only cigarettes and e-cigarettes.

To address the third aim and compare user types, 49 possible W1-W2-W3 pathways were examined across seven mutually exclusive categories (see conceptual map in online supplementary figure 2) among three separate W1 user type categories: (1) P30D exclusive ENDS users (online supplementary table 1a), (2) P30D ENDS polytobacco users w/CIGS (online supplementary table 1b), and (3) P30D ENDS polytobacco users w/o CIGS (online supplementary table 1c). Pathways from online supplementary table $1 \mathrm{a}-\mathrm{c}$ estimate broad behavioural transitions such as persistent use type, discontinued all tobacco use and tobacco use reuptake which were compared across the three user types.

Among youth (table 1), W1 exclusive P30D ENDS users had higher rates of discontinued all tobacco use $(53.9 \%$ (95\% CI 44.6 to 63.0)) compared with W1 P30D ENDS polytobacco users w/ CIGS (17.9\% (95\% CI 12.2 to 25.6)) and W1 P30D ENDS polytobacco users w/o CIGS (28.3\% (95\% CI 16.6 to 43.8$)$ ).

Among young adults (table 1), W1 exclusive P30D ENDS users had higher rates of discontinued all tobacco use $(45.8 \%$ (95\% CI 35.3 to 56.5)) compared with W1 P30D ENDS polytobacco users w/CIGS (11.9\% (95\% CI 9.5 to 14.9$)$ ) and W1 P30D ENDS polytobacco users w/o CIGS (27.2\% (95\% CI 18.8 to 37.6)). Discontinuing ENDS use but continuing other tobacco use was the highest among W1 ENDS polytobacco users w/CIGS (44.8\% (95\% CI 40.8 to 48.8$)$ ) than ENDS polytobacco users w/o CIGS (28.0\% (95\% CI 19.9 to 37.9)) and exclusive ENDS 


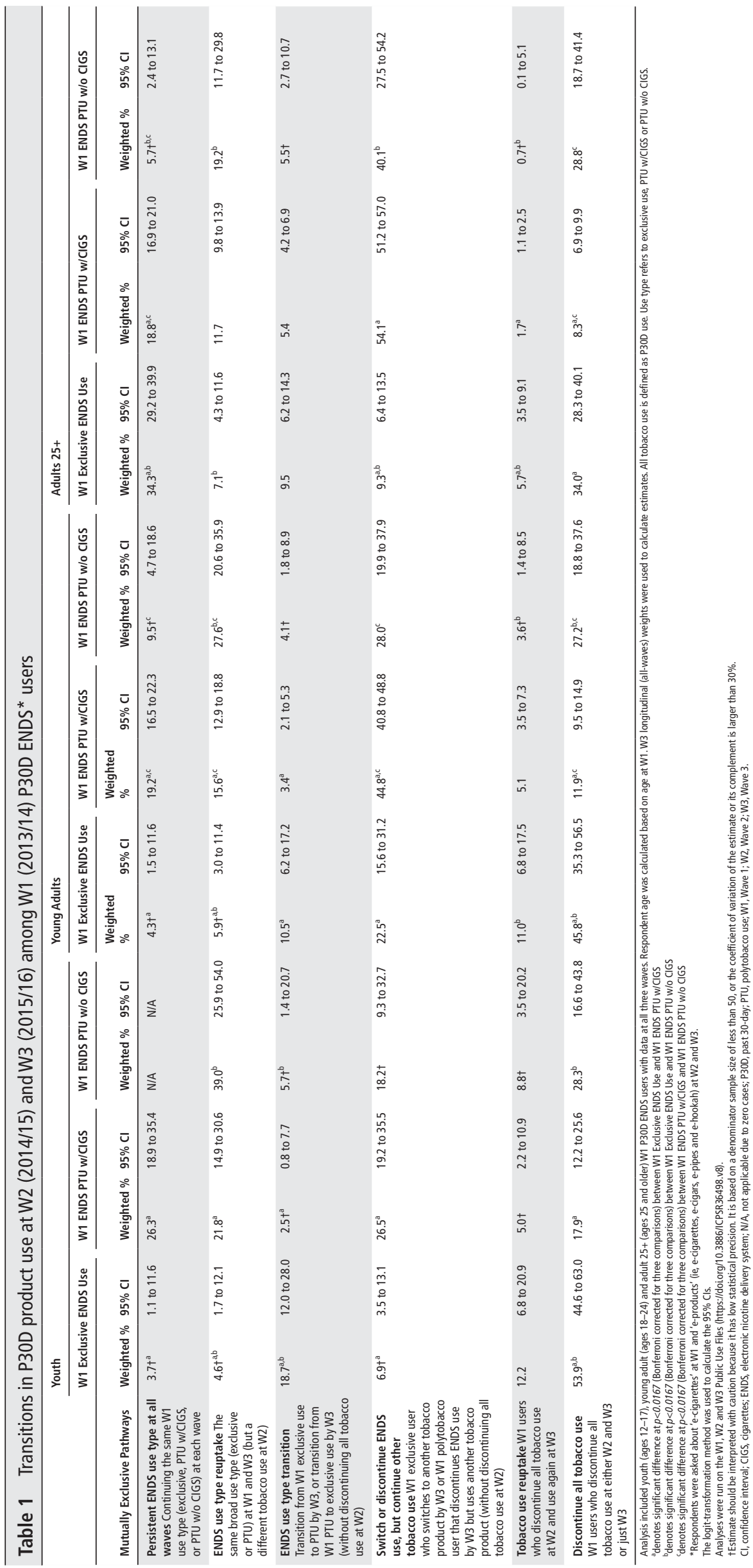


users who switch to other tobacco products by W3 (22.5\% (95\% CI 15.6 to 31.2$)$ ).

Among adults 25+ (table 1), W1 P30D ENDS polytobacco users w/CIGS had the lowest rates of discontinued all tobacco use $(8.3 \%$ (95\% CI 6.9 to 9.9$)$ ) compared with W1 exclusive P30D ENDS users (34.0\% (95\% CI 28.3 to 40.1$)$ ) and polytobacco users w/o CIGS (28.8\% (95\% CI 18.7 to 41.4$)$ ). Similar to young adults, switching from exclusive ENDS to other tobacco products was the lowest among W1 exclusive ENDS users $(9.3 \%$ (95\% CI 6.4 to 13.5$)$ ) compared with W1 ENDS polytobacco users w/CIGS (54.1\% (95\% CI 51.2 to 57.0$)$ ) and ENDS polytobacco users w/o CIGS (40.1\% (95\% CI 27.5 to 54.2)). Persistent use was higher among W1 exclusive ENDS users (34.3\% (95\% CI 29.2 to 39.9)) compared with ENDS polytobacco users w/ CIGS (18.8\% (95\% CI 16.9 to 21.0$)$ ).

\section{DISCUSSION}

As rates of smoking cigarettes continue to decline among US youth and adults, ${ }^{6} 30$ nationally representative cross-sectional surveys have shown an increase in both initiation (new ever use) and P30D ENDS use over the past 5 years, especially among youth and young adults. ${ }^{62031}$ Consistent with other reports, data from the first three waves of the PATH Study found that ever use of ENDS increased at each wave for youth, young adults and adults $25+$. ENDS product availability, device sophistication, e-liquid variability (eg, nicotine salts) and marketing also increased from 2013 to 2016, making access and product awareness a potential reason for increased new ever use over this time period. ${ }^{32-36}$

Differences in trends of ENDS use based on the definition of use were also noted. For example, prevalence of P12M ENDS use did not change among young adults across waves, although among youth it increased $2.5 \%$ from $\mathrm{W} 1$ to $\mathrm{W} 3$, and among adults $25+$ it dropped $2.8 \%$ at W3. Prevalence of P30D use did not change in youth or adults $25+$ from W2 to W3, but among young adults, there was a $4.9 \%$ increase in P30D ENDS use at W3 compared with W2. While generally less than 3\% of P30D ENDS use is daily, daily P30D ENDS use among young adults increased incrementally at each wave (W1, 1.4\% (95\% CI 1.2 to 1.7 ); W2, $2.5 \%$ (95\% CI 2.1 to 3.1 ); W3, 3.0\% (95\% CI 2.6 to 3.4$)$ ); prevalence did not change in youth or adults $25+$. Extending previous reports ${ }^{1}$ compared with youth and older adults, young adults had the highest percentages of P12M, P30D and daily P30D ENDS use at each of the three waves. Thus, young adults are a subpopulation of significant concern if these rising rates of use lead to the potential harms of early exposure to e-cigarette toxins and the well-established harms of subsequent combustible tobacco use. ${ }^{18}$

Longitudinal patterns across the three waves revealed that P30D ENDS use is not stable, with only about a quarter of users having persistent P30D ENDS use at each wave. The most common pattern of use across the three waves was marked by discontinued use, with about half of youth and about $60 \%$ of all adults discontinuing W1 ENDS use for the next 2 years at W2 and W3 or for 1 year at W3. Less than 20\% (18.0\% (95\% CI 14.3 to 22.5$)$ ) of youth, $15.0 \%$ (95\% CI 12.8 to 17.4 ) of young adults and $10.1 \%$ (95\% CI 8.8 to 11.6 ) of adults $25+$ who were W1 P30D ENDS users discontinued ENDS at W2 and then returned to P30D ENDS use at W3. These findings are similar to Coleman et al's findings, in which half of adult e-cigarette users at W1 had discontinued their use of e-cigarettes at W2 and approximately half of W1 dual e-cigarette and cigarette users had discontinued ENDS use at W2. ${ }^{37}$ Thus, despite rising rates of ever use of ENDS, patterns over this 3-year period (2013-2016) showed that ENDS use does not persist among most who try the product.

The majority of ENDS users in each age group also used another tobacco product. There were notably different patterns of ENDS use for exclusive versus polytobacco users (table 1). Among all age groups, more W1 exclusive ENDS users stopped using all tobacco products compared with those with W1 ENDS polytobacco use w/ CIGS. Patterns of use among W1 ENDS polytobacco users w/CIGS were marked by inconsistent use across the waves and discontinued ENDS use but continued use of other tobacco products. Other studies using PATH Study data have shown similar trends in discontinued use between dual users of ENDS and cigarettes compared with exclusive ENDS users. ${ }^{37}$ Moreover, persistent use of ENDS polytobacco use w/CIGS was more common than ENDS polytobacco use w/o CIGS (table 1). These results suggest that ENDS users also using other tobacco products have patterns of use that are not likely to include quitting all tobacco and that these users are more likely to persist either using ENDS with cigarettes or switching to other tobacco products.

Longitudinal patterns of ENDS use over the first three waves of the PATH Study (2013-2016) differ notably from trends presented in parallel reports of PATH Study data focused on other tobacco products. ${ }^{38-41}$ The most common ENDS use patterns over 3 years were either discontinued use, inconsistent use or switching to other products. In contrast, combustible cigarettes and smokeless tobacco products, products that have been on the market in the USA for decades, were used persistently across the waves. Products with rising market presence in the USA, such as hookah and cigars (including little cigars and cigarillos), have more inconsistent patterns of use similar to those of ENDS, particularly among young adults. The literature reports that product characteristics (eg, flavours), ${ }^{42}$ cost and taxation, ${ }^{43} 44$ access in social settings such as vape shops and hookah bars, ${ }^{45}$ as well as differences in targeted marketing and risk perceptions ${ }^{46-48}$ may be driving differences between traditional products and these emerging products, which are poised for intervention to reduce young adults' attraction to these emerging products.

\section{Limitations}

These data predate the rapid increase in ENDS from 2017 to 2018 among youth $^{2720}$ and transition patterns among youth may be different over time. Specifically, data collection occurred before the explosive growth of Juul, which delivers a high dose of nicotine and therefore has a greater potential for addictiveness compared with other ENDS brands, and may reduce rates of discontinued use and increase rates of reuptake. ${ }^{49-52}$ The potential for recall bias from a self-report questionnaire is noted. Additionally, the PATH Study asked about 'e-cigarettes' (the predominant e-product on the market) at W1 and 'e-products' at W2 and W3 which may have resulted in misclassification of ENDS product-specific use between W1 and the subsequent waves. Weighted longitudinal analyses excluded participants who were missing data at one of the waves. The extent of missing data and the small number of observations for low-prevalence pathways may limit interpretation. Other reports suggest that the frequency and intensity of ENDS use may be a critical factor in pathways such as discontinued use and switching. ${ }^{172031}$ Future studies can examine adjusted models to determine which factors predict priority pathways, including frequency of use and other factors that may drive different patterns of use. Kasza $e t a l^{4344}$ and Edwards et $a l^{45}$ examine demographic correlates of initiation, cessation and relapse to further explore predictors of these critical outcomes. 


\section{SUMMARY AND IMPLICATIONS}

Evidence to date suggests that ever use of ENDS among youth may contribute to ever combustible tobacco use. This report identifies patterns of P30D ENDS use that are unstable, with common longitudinal pathways of quitting all tobacco, switching to other products or ENDS polytobacco use with cigarettes. While ever use of ENDS has increased among US youth and young adults, ${ }^{11}$ only a small percentage of the population (less than $1.0 \%$ of youth, $3.0 \%$ of young adults and $1.6 \%$ of adults $25+$ ) were using ENDS daily. Differences in patterns of use among exclusive ENDS users and ENDS polytobacco users were identified, suggesting it is important to make these distinctions. Health education efforts to reduce the appeal and availability of ENDS products might focus on reducing ENDS experimentation, and on reaching the smaller subgroups of ENDS users who are using daily to better understand their reasons for use.

\section{What this paper adds}

- This study includes a three-wave examination of electronic nicotine delivery systems (ENDS) use in the USA across multiple definitions of use for three different age groups. Across all three waves, young adults had the highest percentages of past 12-month, past 30-day (P30D) and daily P30D ENDS use compared with youth and adults 25+.

- While rates of ever use of ENDS increased within each age group, only young adults increased P30D use between W2 and W3. Daily P30D use remained very low (less than 3\%) for all age groups.

- Longitudinal pathways indicate that P30D ENDS use is not stable, as only about a quarter of users showed persistent P30D ENDS use across the three waves.

- The majority of ENDS use is polytobacco use, and ENDS polytobacco users who also use cigarettes are less likely to stop using tobacco 2 or 3 years later compared with exclusive ENDS users.

Contributors CAS and ES led the conceptual design. CAS drafted initial manuscript and all authors critically revised it. ES and MJH conducted statistical analysis and all authors contributed to interpretation of results. All authors approved the work for journal publication and agree to be accountable for all aspects of the work.

Funding This manuscript is supported with federal funds from the National Institute on Drug Abuse, National Institutes of Health, and the Center for Tobacco Products, Food and Drug Administration, Department of Health and Human Services, under a contract to Westat (Contract No HHSN271201100027C).

Disclaimer The findings and conclusions in this report are those of the authors and do not necessarily represent the official position of the US Department of Health and Human Services or any of its affiliated institutions or agencies.

Competing interests WMC reports long-term stock holdings in General Electric Company, 3M Company, and Pfizer Incorporated, unrelated to this manuscript. No financial disclosures were reported by the other authors of this paper.

Patient consent for publication Not required.

Ethics approval The study was conducted by Westat and approved by the Westat Institutional Review Board. All participants ages 18 and older provided informed consent, with youth participants ages 12 to 17 providing assent while their parent/ legal guardian provided consent.

Provenance and peer review Not commissioned; internally peer reviewed.

Data availability statement Data from the PATH Study Wave 1 to Wave 3 are available for download as Public Use Files in a public, open access repository (https://www.icpsr.umich.edu/icpsrweb/NAHDAP/studies/36498). Conditions of use are available at the website above.

\section{ORCID iDs}

Cassandra A Stanton http://orcid.org/0000-0001-5329-6261

Eva Sharma http://orcid.org/0000-0002-1328-508X

Kathryn C Edwards http://orcid.org/0000-0002-0645-1705
Michael J Halenar http://orcid.org/0000-0002-8703-3811

Kristie A Taylor http://orcid.org/0000-0001-6668-7923

Karin A Kasza http://orcid.org/0000-0002-4492-098X

Lisa D Gardner http://orcid.org/0000-0003-3340-2818

Maansi Bansal-Travers http://orcid.org/0000-0002-7944-3570

Heather L Kimmel http://orcid.org/0000-0001-8278-0095

\section{REFERENCES}

1 US Department of Health and Human Services. E-Cigarette use among youth and young adults: a report of the surgeon General. Atlanta, GA: US Department of Health and Human Services, Centers for Disease Control and Prevention, National Center for Chronic Disease Prevention and Health Promotion, Office on Smoking and Health, 2016.

2 Nielsen: Tobacco 'All Channel' Data Through 8/11. Nielsen Total US XAOC/ Convenience Database \& Wells Fargo Securities LLC in Wells Fargo Securities. Nielsen: Tobacco 'All Channel' Data Through 8/11, 2018.

3 Jamal A, Gentzke A, Hu SS, et al. Tobacco use among middle and high school students United States, 2011-2016. MMWR Morb Mortal Wkly Rep 2017;66:597-603.

4 Lee YO, Hebert CJ, Nonnemaker JM, et al. Youth tobacco product use in the United States. Pediatrics 2015:135:409-15.

5 US Department of Health and Human Services. The health consequences of Smoking - 50 years of progress: a report of the surgeon General. 943. Atlanta, GA: US Department of Health and Human Services, Centers for Disease Control and Prevention, National Center for Chronic Disease Prevention and Health Promotion, Office on Smoking and Health, 2014.

6 Wang TW, Gentzke A, Sharapova S, et al. Tobacco Product Use Among Middle and High School Students - United States, 2011-2017. MMWR Morb Mortal Wkly Rep 2018;67:629-33.

7 Gentzke AS, Creamer M, Cullen KA, et al. Vital Signs: Tobacco Product Use Among Middle and High School Students - United States, 2011-2018. MMWR Morb Mortal Wkly Rep 2019:68:157-64.

8 Berry KM, Fetterman JL, Benjamin EJ, et al. Association of electronic cigarette use with subsequent initiation of tobacco cigarettes in US youths. JAMA Netw Open 2019;2: 187794.

9 Singh T, Arrazola RA, Corey CG, et al. Tobacco Use Among Middle and High School Students--United States, 2011-2015. MMWR Morb Mortal Wkly Rep 2016;65:361-7.

10 Arrazola RA, Singh T, Corey CG, et al. Tobacco use among middle and high school students - United States, 2011-2014. MMWR Morb Mortal Wkly Rep 2015;64:381-5.

11 Stanton CA, Sharma E, Seaman EL, et al. Initiation of any tobacco and five tobacco products across 3 years among youth, young adults, and adults in the United States: findings from the path study waves 1-3 (2013-2016). Tob Control 2020;29:5178-90.

12 Zhu S-H, Gamst A, Lee M, et al. The use and perception of electronic cigarettes and snus among the U.S. population. PLoS One 2013;8:e79332.

13 Vardavas $\mathrm{Cl}$, Filippidis FT, Agaku IT. Determinants and prevalence of e-cigarette use throughout the European Union: a secondary analysis of 26566 youth and adults from 27 Countries. Tob Control 2015;24:442-8.

14 Delnevo CD, Giovenco DP, Steinberg MB, et al. Patterns of electronic cigarette use among adults in the United States. NICTOB 2016;18:715-9.

15 Collins LK, Villanti AC, Pearson JL, et al. Frequency of Youth E-Cigarette, Tobacco, and Poly-Use in the United States, 2015: Update to Villanti et al., "Frequency of Youth E-Cigarette and Tobacco Use Patterns in the United States: Measurement Precision Is Critical to Inform Public Health". Nicotine Tobacco Research 2017;19:1253-4.

16 Kasza KA, Ambrose BK, Conway KP, et al. Tobacco-Product use by adults and youths in the United States in 2013 and 2014. N Eng/ J Med 2017;376:342-53.

17 Villanti AC, Pearson JL, Glasser AM, et al. Frequency of youth e-cigarette and tobacco use patterns in the United States: measurement precision is critical to inform public health. Nicotine \& Tobacco Research 2016;19:1345-50

18 Maglia M, Caponnetto P, Di Piazza J, et al. Dual use of electronic cigarettes and classic cigarettes: a systematic review. Addiction Research \& Theory 2017:1-9.

19 Olmedo P, Goessler W, Tanda S, et al. Metal concentrations in e-cigarette liquid and aerosol samples: the contribution of metallic coils. Environ Health Perspect 2018:126:027010.

20 The National Academies Press. National academies of sciences E, and medicine. public health consequences of e-cigarettes. Washington, DC: The National Academies Press, 2018.

21 Shahab L, Goniewicz ML, Blount BC, et al. Nicotine, carcinogen, and toxin exposure in long-term e-cigarette and nicotine replacement therapy users. Ann Intern Med 2017;166:390-400.

22 Goniewicz ML, Gawron M, Smith DM, et al. Exposure to nicotine and selected toxicants in cigarette smokers who switched to electronic cigarettes: a longitudinal within-subjects observational study. NICTOB 2017:19:160-7.

23 Osei AD, Mirbolouk M, Orimoloye OA, et al. Association between e-cigarette use and cardiovascular disease among never and current Combustible-Cigarette smokers. Am J Med 2019;132:949-54.

24 King JL, Reboussin BA, Wiseman KD, et al. Adverse symptoms users attribute to e-cigarettes: results from a national survey of US adults. Drug Alcohol Depend 2019;196:9-13. 
25 Li D, Sundar IK, Mclntosh S, et al. Association of smoking and electronic cigarette use with wheezing and related respiratory symptoms in adults: cross-sectional results from the population assessment of tobacco and health (path) study, wave 2. Tob Control 2020;29:140-7.

26 Hyland A, Ambrose BK, Conway KP, et al. Design and methods of the population assessment of tobacco and health (path) study. Tob Control 2017;26:371-8.

27 Tourangeau R, Yan T, Sun H, et al. Population assessment of tobacco and health (path) reliability and validity study: selected reliability and validity estimates. Tob Control 2019;28:663-8.

$28 \mathrm{McC}$ arthy PJ. Pseudoreplication: further evaluation and applications of the balanced half-sample technique 1969.

29 Judkins DR. Fay's method for variance estimation. Journal of Official Statistics 1990;6:223.

30 Jamal A, Phillips E, Gentzke AS, et al. Current Cigarette Smoking Among Adults United States, 2016. MMWR Morb Mortal Wkly Rep 2018;67:53-9.

31 Glasser AM, Collins L, Pearson JL, et al. Overview of electronic nicotine delivery systems: a systematic review. Am J Prev Med 2017;52:e33-66.

32 Collins L, Glasser AM, Abudayyeh H, et al. And communication: how e-cigarette companies market e-cigarettes and the public engages with e-cigarette information. Nicotine \& Tobacco Research 2018;1:11.

33 Brandon TH, Goniewicz ML, Hanna NH, et al. Electronic nicotine delivery systems: a policy statement from the American association for cancer research and the American Society of clinical oncology. Clin Cancer Res 2015;21:514-25.

34 Wagoner KG, Song EY, King JL, et al. Availability and placement of electronic nicotine delivery systems at the Point-of-Sale. Nicotine \& Tobacco Research 2017.

35 Wagoner KG, Song EY, Egan KL, et al. E-Cigarette availability and promotion among retail outlets near College campuses in two southeastern states. Nicotine tobacco research 2014;16:1150-5.

36 Zhu S-H, Sun JY, Bonnevie E, et al. Four hundred and sixty brands of e-cigarettes and counting: implications for product regulation. Tob Control 2014;23:iii3-9.

37 Coleman B, Rostron B, Johnson SE, et al. Transitions in electronic cigarette use among adults in the population assessment of tobacco and health (path) study, waves 1 and 2 (2013-2015). Tob Control 2019;28:50-9.

38 Taylor KA, Sharma E, Edwards KC, et al. Longitudinal pathways of exclusive and polytobacco cigarette use among youth, young adults, and adults in the USA: findings from the PATH Study Waves 1-3 (2013-2016). Tob Control 2020;29:s139-46.
39 Sharma E, Bansal-Travers M, Edwards KC, et al. Longitudinal pathways of exclusive and polytobacco hookah use among youth, young adults, and adults in the USA: findings from the PATH Study Waves 1-3 (2013-2016). Tob Control 2020;29:s155-62.

40 Edwards KC, Sharma E, Halenar MJ, et al. Longitudinal pathways of exclusive and polytobacco cigar use among youth, young adults, and adults in the USA: findings from the PATH Study Waves 1-3 (2013-2016). Tob Control 2020;29:s163-9.

41 Sharma E, Edwards KC, Halenar MJ, et al. Longitudinal pathways of exclusive and polytobacco smokeless use among youth, young adults, and adults in the USA: findings from the PATH Study Waves 1-3 (2013-2016). Tob Control 2020;29:s170-7.

42 Chen JC, Green KM, Arria AM, et al. Prospective predictors of flavored e-cigarette use: a one-year longitudinal study of young adults in the U.S. Drug A/cohol Depend 2018;191:279-85.

43 Delnevo CD, Giovenco DP, Miller Lo EJ. Changes in the Mass-merchandise cigar market since the tobacco control act. Tob Regul Sci 2017;3:8-16.

44 Gammon DG, Loomis BR, Dench DL, et al. Effect of price changes in little cigars and cigarettes on little cigar sales: USA, Q4 2011-Q4 2013. Tob Control 2016;25:538-44

45 Silveira ML, Hilmi NN, Conway KP. Reasons for young adult waterpipe use in wave 1 (2013-2014) of the population assessment of tobacco and health study. Am J Prev Med 2018;55:650-5.

46 Duke JC, Lee YO, Kim AE, et al. Exposure to electronic cigarette television advertisements among youth and young adults. Pediatrics 2014;134:e29-36.

47 Giovenco DP, Casseus M, Duncan DT, et al. Association between electronic cigarette marketing near schools and e-cigarette use among youth. J Adolesc Health 2016;59:627-34

48 Wackowski OA, Delnevo CD. Young adults' risk perceptions of various tobacco products relative to cigarettes: results from the National young adult health survey. Health Educ Behav 2016;43:328-36.

49 Willett JG, Bennett M, Hair EC, et al. Recognition, use and perceptions of JUUL among youth and young adults. Tob Control 2019;28:115-6.

50 Miech R, Johnston L, O'Malley PM, et al. Adolescent Vaping and Nicotine Use in 2017-2018 - U.S. National Estimates. N Engl J Med 2019;380:192-3.

51 Vallone DM, Bennett M, Xiao H, et al. Prevalence and correlates of JUUL use among a national sample of youth and young adults. Tob Control 2019;28:603-9.

52 Hammond D, Wackowski OA, Reid JL, et al. Use of JUUL e-cigarettes among youth in the United States. Nicotine Tobacco Research 2018:66. 